INTERNATIONAL JOURNAL FOR

HISTORY, CULTURE AND MODERNITY

www.history-culture-modernity.org

Published by: Uopen Journals

Copyright: (c) The Author(s).

Content is licensed under a Creative Commons Attribution 4.0 International Licence

eISSN: 2213-0624

\title{
Ordering Disability. How Can Modernity Theory Inform Disability History?
}

Paul van Trigt

HCM 7: 423-442

DOI: $10.18352 / \mathrm{hcm} .564$

\begin{abstract}
What are the advantages and disadvantages of applying modernity theory to 'disability history'? Giving voice to people with disabilities, disability history aims to show how disability is a part of broader, complex power relations in society. The article discusses several possible approaches. The framework of modernity and eugenics developed by Zygmunt Bauman is shown to be too one-sided for disability history. Ulrich Beck's modernity theory proves to be more useful. Actor Network Theory (ANT), and in particular the theory developed by Annemarie Mol, offers the most sophisticated approach to disability history. ANT enables disability historians not only to give voice to people with disabilities, but also to approach disability as existing in multiple ways. This allows scholars to take into account seriously criticism of the influential, so-called 'social model' of disability.
\end{abstract}

Keywords: abortion, Actor Network Theory (ANT), disability, modernity, risk

\section{Introduction $^{1}$}

Historians understand disability and consequently analyse it in different ways. Although they usually consider the concept itself, and the context in which it arose, to be a 'modern' one, they rarely explore how historical interpretations of disability are influenced and could be improved by modernity theory. On some occasions the history of disability is put 
forward as a way to give voice to people with disabilities and include them in modernity, while on other occasions disability history is used to criticize the ableism inherent to modernity. However, in both cases little attention is paid to the role of modernity theory, at least not explicitly. ${ }^{2}$ In what follows, I will discuss the advantages and disadvantages of applying modernity theory to disability history.

The emergence of disability history is closely related to the struggle in recent decades for the emancipation of people with disabilities. ${ }^{3}$ Since the I980s, and in particular in the Anglophone context, disability history developed in the slipstream of disability activism, and as part of the field of disability studies. The so-called social model of disability, which understands disability as a social construct, was seen as the very core of the disability movement. ${ }^{4}$ Disability had, of course, been studied by historians before that time, but, as advocates of disability history point out, this happened too often from an exclusively medical or institutional point of view. Cathy Kudlick points out that disability history needed a foundation cemented in 'two core political ideas, both rooted in the disability rights movement: a need to challenge the prevailing assumptions about disability, and the importance of granting people with disabilities historical agency'. ${ }^{5}$ Although the link to disability politics is not always explicitly made, the still increasing number of publications on disability history support Kudlick's contention.

At the same time, the ambition to add yet "another "other"" to the mainstream historian's conceptual toolbox seems more difficult to realize. Disability is still not used as frequently as other categories of historical analysis such as gender, class and ethnicity. Disability is mainly treated by historians as 'a subject worth studying in its own right', not as 'a new analytic tool for exploring power itself' ${ }^{6}$ In consequence, disability history runs the risk of remaining isolated in mainstream history writing. The challenge to add 'another other' can be taken up by doing more intersectional analysis, in which multiple social categories are taken into consideration, but also by relating disability to broader theoretical frameworks. ${ }^{7}$ This is what I want to investigate in this article. Modernity theory offers a relevant framework in this regard, not only because disability history aims to show how disability always has been part of the complex power relations in modern society, but also because in the globalized world modernity itself is no longer a 
self-evident framework. ${ }^{8}$ The fact that historians are increasingly writing about disability in the global South makes reflection on modernity theory necessary.

In the following I will evaluate the (dis)advantages for disability history of three currents in modernity theory, represented by Zygmunt Bauman, Ulrich Beck and Annemarie Mol, in the context of ongoing debates in the field disability studies. Because disability history aims to give voice to people with disabilities, I will ask in particular how the work of these three scholars enables us to make that voice heard. ${ }^{9}$ Bauman's work is my point of departure because he explicitly addresses disability and because his work is already used by prominent disability scholars. Beck is chosen not only because he is one of the most influential thinkers about modernity, but also because his work, as I will argue, seems to offer a refined version of Bauman's theory. Mol's work is not directly related to that of either Bauman or Beck, but it is relevant for disability research because of its focus on the body and on medicine. Mol's take on modernity and Actor Network Theory (ANT) in my view offers the most promising theoretical framework. In the final section I will elaborate on the way ANT could further inform a global disability history.

I will illustrate my arguments on the basis of recent political debates about prenatal screening and abortion in the Netherlands, with which I am familiar. However, the Dutch case has parallels with similar debates elsewhere, for instance Ireland. Abortion is often framed in terms of modernity, but in debates on abortion people with disabilities are rarely heard. ${ }^{10}$ The Dutch case enables me to clarify different relations between disability and modernity.

\section{From Politics to Modernity Theory}

Debates on abortion often refer to disability. ${ }^{\mathrm{II}}$ With the recent adoption by the United Nations of the International Convention on the Rights of Persons with Disabilities (UNCRPD, 2006), and its worldwide implementation, a new element has been added these debates. Although the inclusion of the 'right to life' in the convention cannot be interpreted as "inherently "pro-life" or "pro-choice", as Bret Shaffer has argued, the convention has fuelled debates between pro-life and pro-choice actors. 
This becomes clear from the Dutch case. ${ }^{12}$ In one of the discussions about the UNCRPD in the Dutch parliament, Gert Jan Segers, a member of a small Christian political party, the Christen Unie, pointed out the government's 'double standard'. The government intended to foster an inclusive society while at the same time it made the Non-Invasive Prenatal Test (NIPT, also known as the 'Down test') available to pregnant women. Does the government, Segers asked, do enough to improve the social position of people with Down Syndrome, in such a way that the women involved need not fear exclusion and do not feel obliged to choose an abortion? Before the state secretary responsible for this issue could answer, Vera Bergkamp, a member of the liberal democratic party D66, interrupted Segers: was he merely underlining the importance of good information provision, or did he want to prohibit the NIPT? The latter was clearly not an option for Bergkamp. ${ }^{13}$ The debate illustrates how discussions related to abortion have been dominated by the opposition between religious or conservative pro-life actors on the one hand, and liberal and/or feminist pro-choice actors on the other. In this particular debate the politicians agreed in the end on the importance of good and honest information provision. However, a debate on the consequences of prenatal diagnostics for social diversity, a debate some disability activists want to initiate, was never really held. ${ }^{14}$

This case could easily be framed in terms of modernity if we formulate the opposition as one between 'modern' liberals and 'traditional' believers, or one between 'progress' (favouring women's rights) and 'conservativism' (favouring the rights of unborn children). From a disability history perspective, however, one can ask whether new technologies of prenatal screening do not add a new dimension to such debates, one that transcends such oppositions: the inclusion and exclusion of people with disabilities. In 1994, for the first time in the Netherlands, people with disabilities had organized a conference on prenatal diagnostics. However, their critical perspectives have had little influence on political parties, as the recent debate about the UNCRPD shows. ${ }^{15}$ How can we bring disability into the analysis of this debate in a meaningful way?

An obvious framework within which to address the position of people with disabilities in the context of prenatal diagnostics and abortion is that of eugenics. As disability scholars David Mitchell and Sharon Snyder have argued, disability, like race, can be analysed as one of the 
'projects of human exclusion, based upon scientific management systems, successively developed within modernity'. People with disabilities have been discriminated against because of 'eugenics discourses on disability: marriage restriction laws against people with cognitive disabilities, coerced sterilisation, routine institutionalisation, mandated segregation in schools, class-based communicates of the homeless, sheltered workshops and farm colonies all make up a social landscape occupied by those designated as existing at the bottom rungs of social ladders of being'. ${ }^{16}$ The prevention of people with disabilities from being born, enabled by screening and abortion, could be fitted into this framework.

In describing disability as 'the master trope of disqualification in modernity', Mitchell and Snyder follow sociologist Zygmunt Bauman, who wrote about the exclusion of groups in modern societies. ${ }^{17}$ Social historian Leo Lucassen has explained the usefulness of Bauman's modernization theory in his work on social engineering in Europe. According to Lucassen, Bauman describes

modernity as a process in which to promote greater individual security people are willing to forego a degree of freedom. The managing of risks and uncertainties is left to bureaucracies, which in turn are expected to create order in the chaos of society. Everything which the responsible authorities believe threatens social stability is automatically regarded as a problem.

This perspective enables us to understand eugenics in a broad sense, as consisting not only of biologistic ideas and practices, but also of 'measures to curtail the rights of individuals under the pretext of protecting society from the "social locus of infection". ${ }^{18}$ In this framework, modernity and eugenics are intertwined, and disability is at the core of this intertwinement.

However, does the interpretation of prenatal diagnostics (in combination with abortion) as a revival of eugenics make sense, at least in the case of the Dutch abortion debate? It is possible to understand prenatal diagnostics as a new regime of eugenics, but does this allow us to see the complex relations between technologies and politico-ethical debates? And does the concept of eugenics make it possible to analyze paradoxical positions, like those of advocates of prenatal diagnostics and abortion who both support the right of people with disabilities to 
exist and believe it is a good thing to prevent disabilities? Although the eugenics narrative is necessary to understand these debates, it does not really shed light on how historical actors position themselves.

\section{The Concept of the Risk Society}

Could Ulrich Beck's theory of modernity and in particular his work on the risk society be usefully applied to the debates on disability? Beck employs the concept of risk to analyze society not as the outcome of a progressive or regressive historical process, but as a new form of modernity replacing industrial society. According to Beck the transition from the industrial to the risk society has three characteristics: (I) 'the axial principle of industrial society is the distribution of goods, while that of the risk society is the distribution of "bads" or dangers'; (2) 'industrial society is structured through social classes while the risk society is individualized'; and (3) 'the gain in power from techno-economic "progress" is being increasingly overshadowed by the production of risks'. ${ }^{19}$ Beck does not frame these developments as postmodern, but as 'more modernity, a modernity radicalized against the paths and categories of the classical industrial setting'. Compared to the eugenic modernity discussed above, the concept of the risk (society) has the advantage that it is not a judgemental term. As will become clear, the concept can be used for my case study, but because Beck based it 'on the assessment that we are eye-witnesses - as subjects and objects - of a break within modernity', and because the risk society is often seen as a recent development, it is unlikely that we can use his concept for long-term histories of disability. ${ }^{20}$

The concept of the risk society also has the advantage of rendering visible how societies are determined, intentionally or not, by new technologies. Both historical actors and historians tend to see technologies as neutral givens with respect to which we then take in an ethical position. In the case of abortion this ethical position is often determined by different ('modern' or 'traditional') perspectives on the autonomy of women. But the case described in this article shows that a technique like ultrasonography can also add a new dimension to the ethical debate, because ultrasound scans in combination with the option of an abortion enable parents to identify and remove a foetus with a disability or an illness. Such an action implies that disability is a problem that has 
to be solved. This is easier to articulate within the framework of the risk society, involving 'a systematic way of dealing with hazards and insecurities induced and introduced by modernisation itself', and which has an eye for paradoxes, than in the more straightforward framework of eugenics and modernity. ${ }^{21}$ However, applying the risk society to my case is also slightly atypical, as Beck coined the concept with major global risks in mind.

Furthermore, the notion of the risk society can be used to understand why it is so difficult for disability activists, who reject a negative perspective on disability, to address this issue. This is not only because the abortion debate is dominated by an often religious pro-life movement, but also because they too live in a society that wants to reduce insecurities and human suffering at all costs. The humanitarian aim to reduce human suffering is rather neglected by Beck, but I think it helps us understand why risk is such a dominant concept in society. The ideal of a life without suffering makes it almost impossible for disability activists to explain that taking the risk of suffering could be worthwhile. ${ }^{22}$ Beck's assumption that risk is a characteristic feature of (Western) societies since the I970s can be criticized on the ground that societies have had a much longer history of dealing with risk in relation to scientific and technological activities. Risk, however, did become more pronounced in the last decades of the twentieth century. ${ }^{23}$ We can therefore use the notion of the risk society to grasp the expression of a dominant idea in society. In this sense, Beck's work is not used as a theory with explanatory power, but as the expression of an idea that helps us explain why historical actors have acted in a particular way. ${ }^{24}$

The same can be argued for individualization, a concept that features in Beck's Risk Society alongside risk as a core element of 'reflexive modernization'. Framing abortion as an matter of individual choice seems to fit well with Beck's approach to individualization, which focuses on increased freedom of choice. Like other scholars he tends to regard the recent decades as a period of individualization, in which people increasingly see themselves as individuals who have to make choices. ${ }^{25}$ This view has been criticized because the concept of individualization obscures how people collectively see themselves as individuals, and often make choices as a group, although they experience this as making an authentic individual choice. ${ }^{26}$ Individualization as an analytical concept does not help the historian in understanding these 
new ways of collective acting, but individualization as an expression of a dominant idea in society certainly does.

This evaluation makes clear that Beck's theory can be used to refine the relationship between disability and modernity because it distorts modernity as a linear process and points to the dominance of both risk and the individual since the I970s. However, the shift in the I970s assumed by Beck can be questioned from an historical perspective. Moreover, the risk society, like other modernization theories, is focused on tracing general, dominant trends. This makes it far from ideal to articulate deviant developments and marginal voices. In what follows, I will argue that disability history can further benefit from work by scholars associated with Actor Network Theory (ANT).

\section{Modes of Ordering}

While the diversity of work on ANT makes it difficult to characterize it, ANT scholars share a number of characteristics: 'a set of sensitivities', an 'adaptable, open repository', 'a list of terms' ${ }^{27}$ One of the frequently used terms that is particularly relevant for my purposes is John Law's term 'modes of ordering'. In Organizing Modernity (I994) he defines this as 'fairly regular patterns that may be usefully imputed for certain purposes to the recursive network of the social. In other words, they are recurring patterns embodied within, witnessed by, generated in and reproduced as part of the ordering of human and non-human relations' ${ }^{28}$ Law developed the concept in relation to the Foucauldian concept of discourse, because 'there is relatively little about process' in Foucault's work. Law proposed to distinguish five dimensions of discourse:

first, we should treat it as a set of patterns that might be imputed to the networks of the social; second, we should look for discourses in the plural, not discourse in the singular; third, we should treat discourses as ordering attempts, not orders; fourth, we should explore how they are performed, embodied and told in different materials; and fifth, we should consider the ways in which they interact, change, or indeed face extinction. ${ }^{29}$

It is easy to see how this view enables us to trace dominant as well as marginal modes of ordering, which are both important to understand the case at hand. 
Annemarie Mol, another scholar working on ANT, has demonstrated the usefulness of Law's concept in The Logic of Care (2008). On the basis of anthropological fieldwork in hospitals she articulated two modes of ordering, or two logics (ways of thinking and acting), in healthcare: a logic of care and a logic of choice. The latter seems to dominate healthcare today, as a result of the (neoliberal) market model, which uses terms like clients, products and management. Mol argued however that the logic of choice does not always fit with the ways of thinking and acting in the practice of healthcare. These can be more adequately described and articulated by the logic of care, using terms from the ANT list such as ordering and tinkering. ${ }^{30}$ By doing this Mol uses 'etic' concepts to articulate what is not visible or observable when only 'emic' language is analyzed. Used in this way, the concept of modes of ordering, or logics, would be helpful in analyzing prenatal screening because it challenges us to look for a variety of attempts at ordering and for the ways in which modes of ordering relate to each other. This allows us to clarify how disability is part of broader, complex orderings in society, and how the voice of people with disabilities could be articulated.

Moreover, ANT concepts and the assumption about the relevance of non-human actors that underlies them enable us to take into account the role of technology, as scholarly work on the transformative power of ultrasonography has done. ${ }^{31}$ Prenatal screening has not only changed the relations between the 'personified' foetus and expectant mother(s) and/or father(s), but has also medicalized pregnancy and childbirth. Ingrid Zechmeister has even written about the foetus as a patient..$^{32}$ These studies make clear that the developments in prenatal diagnostics have added a new aspect to the abortion debate. More than ever, expectant parents have to take into consideration whether they want to take the risk of having a child with a disability or illness. New technologies have made parenthood of children with a disability or illness seemingly an issue of choice. Taking the new technologies of prenatal diagnostics seriously was an option also provided by the framework of Beck's theory of the risk society. What does ANT add to this in the light of disability history's aim to take into account the inclusion or exclusion of people with disabilities?

The added value of ANT and the concept of modes of ordering is that they raise awareness of the coexistence of different orderings. Modernization theory can help us understand the dominant mode of 
ordering, but is often less helpful in understanding more paradoxical stances: actors who support both the inclusion of people with disabilities and the freedom of aborting a disabled foetus, or people who had serious concerns about this freedom but fought for freedom of choice in other cases. The marginality of a disability perspective, as is the case in the Dutch abortion debate, cannot be understood as just a consequence of the social exclusion of people with disabilities. It also has to do with the variety of perspectives among people with disabilities and their organizations. People with disabilities often have alternative views on preventing suffering, but since there is no Dutch disability movement such as the gay rights movement, positive images to counter the negative images of disability were never fully developed. ${ }^{33}$ Looking through the lens of modes of ordering enables us to see these complexities, and to point out unintended exclusions and unknown alternatives.

ANT thus offers a fruitful way to show how disability was part of the broader, and complex network of relations of power in modern society, but it also has the potential to question the way modernity theory underlies disability history itself. Thanks to the work of, for instance, Pieter Verstraete, the 'modernist critique' has already found its way into disability history, but now that writing disability history is increasingly becoming a global affair, more reflection on the modern underpinnings of disability movements is needed. ${ }^{34}$ Despite the global trend in disability history, the Anglophone disability movement and the social model it proposes are still often seen as self-evident and exemplary: it is often implied that developments in disability policy first took place in an Anglophone context, or at least that the Anglophone disability rights movement is a model against which to measure progress. ${ }^{35}$ This is not always helpful in understanding local particularities or seeing translocal relations - an urgent matter in the context of the global South. ${ }^{36}$ ANT offers an approach to the concept of disability itself, of which disability history can take advantage, as I will make clear in following section.

\section{ANT and the Social Model of Disability}

In particular Annemarie Mol's work provides a perspective on approaching disability and the disabled body from an ANT perspective. In The 
Body Multiple (2002) she argues that bodies never simply 'are', but have to be enacted. The body is a question of relationality: to what is the body related, and how is it situated in a network of relations? By stressing the particularity of the enactment, determined by place, time, material conditions and other factors, Mol demonstrates the very multiplicity of the body. For example, the body and its diseases appear very differently in an X-ray image than in an interview with a patient in a doctor's surgery. Although scholars understand disability increasingly as a relational concept, ANT in general and Mol's work in particular are barely referred to in disability studies. ${ }^{37}$

This is striking, for parts of Mol's theory seem to fit in well with recent developments in disability studies, such as critical disability initiatives as well as more body-oriented approaches, both of which share a critical attitude towards social constructivism and the social model of disability. ${ }^{3}$ Moreover, for the global South it has been argued that disability not only needs to be conceptualized in terms of social dynamics (the social model), but also that it is important to capture the social dynamics in the body itself. ${ }^{39}$ The importance of the social model for both disability activism and disability studies lies in the change of perspective it brings about, by giving people an alternative to the medical perspective according to which disability is only an individual deficit. Rather than viewing disability as primarily concerned with the body, the social model holds that it is a construct of society. This insight has long been a source of inspiration to activists and academics alike. $4^{40}$ Lately, however, the social model, in particular the ignorance of the body it entails, have been heavily contested. In this respect ANT may stimulate the transcending of prevailing distinctions, for instance between social and non-social and between culture and nature, in order to develop new approaches to disability. ${ }^{41}$ The potential of this approach has scarcely been recognized. An exception is an article by Vasilis Galis..$^{42}$ I will briefly summarize his contribution before further developing my own argument.

Galis takes as his starting point the assertion of Corker and Shakespeare that 'the global experience of disability is too complex to be rendered within one unitary model or set of ideas' ${ }^{43}$ On the basis of studies about disability from the perspective of science and technology studies (STS), which is strongly related to ANT, Galis argues for an understanding of disability as 'done within various practices 
and through different experiences', rather than as medical and social constructions. ${ }^{44}$ STS can contribute to disability studies, according to Galis, through the concept of actor networks, which he defines as 'interconnected complexes through which human and non-human entities evolve, interact and produce effects, such as the loss of function or a diminished ability to function, or disability'. ${ }^{45}$ In this approach, the rational independent modern subject is no longer the central unit that it tends to be in the social model. Moreover, the presence of non-human entities renders it impossible to maintain the division between society and nature or to speak about social constructivism. Galis adds a critical note to this positive evaluation of ANT: ANT insufficiently enables the recording of discriminations against and the exclusions of actors. Galis accordingly argues for the involvement of concerned groups, such as disability groups who possess valuable expertise and experience, which ANT would be likely to overlook.

Galis's recommendation has yet to be applied in any substantial way. Some disability research is carried out on the basis of STS or ANT, but scholars in disability studies and history generally tend to ignore ANT as a theoretical alternative to the social model of disability. Although the social model is now contested in disability studies, it remains important. It seems, for example, to underlie the United Nations Convention of the Rights of Persons with Disabilities, in which numerous articles refer to boundaries in society that can render people disabled.

How can the social model be evaluated from the ANT perspective? What is important in this respect is the word 'social', as discussed by Bruno Latour in Reassembling the Social (2005), a key publication for ANT. Latour states that the use of the concept social is permitted only as an adjective to describe a phenomenon. Problems arise when 'social' begins to mean 'a type of material' or 'a domain of reality' and when 'social explanations' are provided. ${ }^{46}$ Latour does not want to understand society as 'a stable and absolute third term in which to translate all the vocabularies of the informants'. He asks, 'will we have the courage not to substitute an unknown expression for a well-known [social] one?' because he resists 'the idea that there exists somewhere a dictionary where all the variegated words of actors can be translated into the few words of the social vocabulary' ${ }^{47}$ In this respect, Latour rejects the adjective social in relation to constructivism because that would suggest that 'we [can] replace what this reality is made of with some other stuff, the social in 
which it is "really" built'.$^{8}$ Parallel to his critique (although he probably would not like the word critique) of 'the social' he has also questioned 'nature' as an objective reality that is not a part of social construction. ${ }^{49}$

How does this critique relate to the social model of disability? In the first place, the concept of the 'social' is often used in disability research in a way that Latour would advise against. The social model posits that 'society disables', which for scholarly analysis is too general a statement. This does not mean the social model is not relevant to the disability rights movement. It is an important alternative for the one-sided medical model. ANT has to be open to it, following Latour's advice: 'Let the actors do the job for us. Don't define for them what makes up the social!' ${ }^{\circ}$ In the case of disability history, we have to historicize the social model. How did disability activists define and use (or not use) it? This perspective can be useful when one wants to understand the marginal voice of people with disabilities, for example in the Dutch prenatal screening debate. Historical research in the Netherlands on the social model of disability has shown that it has not functioned as an inspiration for disability activism to the extent it did in other countries. ${ }^{51}$

In the second place the social model of disability is a modern model and therefore problematic from the perspective of a Latourian 'beyond modernity'.$^{22}$ The model is grounded in the dissociation between the social or cultural and the natural world: disability is a social construct and impairment is a natural phenomenon. The body was banned by disability activists for a long time, with the exception of some feminists. Disability was discussed only in terms of barriers in society. Although the body is now 'back on track', the dissociation between culture and nature is still very much alive. Scholars often present attention to the body as a mere addition to the social model. ${ }^{33}$ As Tom Shakespeare has put it, 'People are disabled by society and by their bodies and minds'. ${ }^{54}$ ANT challenges us to go one step further. We have to historicize nature and the body as well. The nature / culture distinction often comes to the fore when it is argued in disability research that an impairment has 'always already existed'. Shakespeare, for example, defines Down Syndrome as 'an intellectual impairment caused by having three copies of chromosome $2 \mathrm{I}$ '.55 From the point of view of ANT, an unchanged natural reality next to a social reality consisting of changing constructions of disability is not conceivable. An impairment or disability exists only as it is enacted. We cannot assume a timeless body. 


\section{Theory and Politics}

In her work on the body, care and politics, Annemarie Mol has demonstrated the importance of multiplicity. ${ }^{56}$ Applying her approach to disability, entails discerning multiple ways in which disability can exist, sometimes as an individual impairment (medical model), sometimes as a societal construction (social model), to mention just two possibilities. Recognizing multiplicity seems particularly relevant for a global perspective on disability history because it resonates with the insights of the 'ontological turn' in anthropology. It has been claimed, for instance, that 'the Araweté people do not simply have a different culture from ours but also a different nature because they have a different culture (and vice versa).' ${ }^{57}$ Similarly, Galis has argued that ANT makes it possible to see disability as 'a simultaneous biological material and semiotic phenomenon', but he seems to interpret multiplicity (different realities) as plurality (different perspectives of one reality). ${ }^{8}$ Nevertheless, ANT seems able to support an approach to disability that does justice to the richness and complexity of disabled people's lives in past and present as well as in different places.

What about politics? Does ANT allow disability history to be politically engaged? ANT is often criticized for its lack of political and critical potential, as Galis has hinted. In this respect it is helpful to take into consideration what historians Roger Cooter and Claudia Stein have argued in response to the way Patrick Joyce has employed Latour's theory and ANT. Cooter and Stein describe ANT as follows:

In the face of a sociology of human interactions which presupposes something inherent to the world and which believes it capable of being revealed or discovered, ANT posits a sociology of interaction between 'thing or objects or beasts' in which each 'actant' (so called) is regarded as important as the other, and from the observation of which interactions no discernible outcome is to be preconceived. ${ }^{59}$

The authors emphasize that for Latour society does not exist 'because it is ever in-the-making by the associations of actants' ${ }^{60}$ Behind ANT lies, according to Cooter and Stein, 'the conviction that the world today is surprisingly unpredictable, ever changing and highly contingent' ${ }^{6}{ }^{61}$ Moreover, ANT 'substantiates that we now inhabit a place where 
people and things must be kept in constant circulation' and thus substantiates 'the world of neoliberalism'. ${ }^{62}$ Cooter and Stein's point is not that Latour and Joyce are neoliberals, but they are afraid that ANT 'leaves little space for reflection on the moral or ethical standpoint of the historian' ${ }^{63}$ Joyce does not, according to Cooter and Stein, critically question the (political) present. Inspired by Foucault, Cooter and Stein in contrast propose a critique that is aware that 'the categories involved in criticizing are themselves historically composed' ${ }^{64}$

It follows that (self-)reflection about the position of the historian is needed. When 'follow the actor' is the motto, the researcher can in fact remain invisible. ${ }^{65}$ At the same time, scholars have already shown that ANT has critical potential. In the Logics of care, Annemarie Mol has dealt with this issue by explaining that she wants to move away from a focus on who is allowed to say something to the question of what there is to say. ${ }^{66}$ As we have seen in the case of prenatal screening, this could be a good strategy for disability history: the articulation of disability in the political debate already sheds a critical light on existing power relations without losing a sense of complexity. Moreover, the aim of giving people with disabilities a voice by no means disappears. ANT will also challenge us to consider the question whether people with disabilities have or want to have a voice in this debate. In doing so, ANT shows that nothing is given and everything is contingent, and that seems to be a good starting point for an engaged disability history.

\section{Conclusion}

In this paper I have investigated how modernization theory as a broader framework can inform disability history, which aims to give voice to people with disabilities and show how disability is a part of broader, complex power relations in society. I have used the Dutch abortion debate to argue that the framework of modernity and eugenics as developed by Zygmunt Bauman results in a one-sided approach to disability history. I have also evaluated the usefulness of Ulrich Beck's modernity theory for understanding the marginality of disability and concluded that his theory provides a partial explanation, but does not enable us to articulate the voice of people with disabilities. Furthermore, I have evaluated the value of ANT, in particular in Annemarie Mol's work for 
better understanding the Dutch debate. ANT can be characterized as a theory 'beyond modernity'. The concept of modes of ordering enables us, as I have argued, to include the voice of people with disabilities and to develop a more sophisticated approach. Finally, I have further underlined the usefulness of ANT for a global disability history by showing how disability can be seen as existing in multiple ways, a perspective that enables us to question the powerful social model of disability and take seriously recent criticism of the modern axioms of this model.

\section{Notes}

I The author wishes to thank Filip de Greef, Anaiis van Ertvelde, the anonymous reviewers and IJHCM's editors for their comments on earlier versions of this article. He acknowledges the support of the ERC Consolidator Grant Rethinking Disability under Grant Agreement 648 I I 5 .

2 Cf. Sue Donaldson and Will Kymlicka, 'Rethinking Membership and Participation in an Inclusive Democracy: Cognitive Disability, Children, Animals', in Barbara Arneil and Nancy Hirschmann (eds), Disability and Political Theory (Cambridge, 2016) I68-97.

3 Catherine J. Kudlick, 'Disability History: Why we Need Another "Other", The American Historical Review I08:3 (2003) 763-93.

4 Paul van Trigt, 'Historicizing the Social Model: Some Preliminary Thoughts About the History of Disability, Science, and Politics in Postwar Britain and the Netherlands', Studien des Aachener Kompetenzzentrums für Wissenschaftsgeschichte I7 (2017) 93-I03.

5 Catherine J. Kudlick, 'Comment: On the Borderland of Medical and Disability history', Bulletin of the History of Medicine, 87:2 (2013) $540-59$.

6 Kudlick, 'Disability History', 765; Paul L. Longmore and Lauri Umansky (eds) The New Disability History: American Perspectives (New York, 200I); Pieter Verstraete, In the Shadow of Disability: Reconnecting History, Identity and Politics (Opladen, 20I2); Susan Burch and Michael Rembis (eds.) Disability Histories (Urbana, Chicago and Springfield, 20I4).

7 Cf. D. van Arkel, The Drawing of the Mark of Cain. A Social-historical Analysis of the Growth of Anti-Jewish Stereotype (Amsterdam, 2009).

8 Monika Baar, 'De-Pathologizing Disability: Politics, Culture and Identity', Neue Politische Literatur 62 (2017) 28 I-303. 
9 Catherine, 'Comment'.

Io An important exception (that was published when this article was almost ready) is the analysis of the German abortion debate: Dagmar Herzog, Unlearning Eugenics: Sexuality, Reproduction, and Disability in Post-Nazi Europe (Madison, Wisconsin 2018).

I I Tom Shakespeare, Disability Rights and Wrongs Revisited (London, New York, 20I4), in particular Chapter 6.

I2 Bret Shaffer, 'The Right to Life, the Convention on the Rights of Persons with Disabilities, and Abortion', Penn St. International Law Review 28:2 (2009) 265-87.

I3 Minutes of this parliamentary debate (January 20I6) are available at https://www.tweedekamer.nl/kamerstukken/detail?id=20 I6Do2570\&did= 20I6Do2570 (accessed 7 July 20I7).

I4 The main initiative was the publication, by the organization Downpride, of a Blackbook Down: 'a collection of first hand testimonies from over I40 parents who felt they were steered towards a "choice" or "misinformed" about Down syndrome': https://downpride.com/blackbook-down (accessed 7 July 2017).

I5 The I994 debate is mentioned by Jan Troost, 'Erfelijke aandoeningen: het cliëntenperspectief', in H. Schellekens (ed.), Medische biotechnologie (Maarssen 200 I) I 85-96, at I93-4.

I6 David Mitchell and Sharon Snyder, 'The Eugenic Atlantic: Race, Disability, and the Making of an International Eugenic Science, I800-I945', Disability \& Society I 8:7 (2003) 843-64, at 860.

I7 Mitchell, 'Eugenic Atlantic', 86I; Zygmunt Bauman, Modernity and the Holocaust (Cambridge, I989).

I 8 Leo Lucassen, 'A Brave New World: The Left, Social Engineering, and Eugenics in Twentieth-Century Europe', International Review of Social History 55 (20 I0) 265-96.

I9 Ulrich Beck, Risk Society. Towards a New Modernity (London I992) 2-3, I3.

20 Beck, Risk Society, 9, I4.

2 I Ibid., 2 I.

22 Cf. Luc Boltanski, Distant Suffering. Morality, Media and Politics (Cambridge, I999).

23 Soraya Boudia and Nathalie Jas, 'Introduction: Risk and 'Risk Society' in Historical Perspective', History and Technology: An International Journal 23:4 (2007) 3I7-3I. A search on the term 'risk' in Google Books Ngram Viewer indicates an increase in the use of this concept (https://books. google.com/ngrams, accessed 22-04-2019). 
24 Cf. Rüdiger Graf and Kim Christian Priemel, 'Zeitgeschichte in der Welt der Sozialwissenschaften. Legitimität und Originalität einer Disziplin', Vierteljahrshefte für Zeitgeschichte 59 (20 I I) 479-508.

$25 \mathrm{Cf}$. Ulrich Beck and Elisabeth Beck-Gernsheim, Individualization. Institutionalized Individualism and its Social and Political Consequences (London, 2002).

26 Bram Mellink, Worden zoals wij. Onderwijs en de opkomst van de geïndividualiseerde samenleving sinds I945 (Amsterdam 20I4).

27 Annemarie Mol, 'Actor-Network Theory: Sensitive Terms and Enduring Tensions', Kölner Zeitschrift für Soziologie und Socialpsychologie 50: I (2010) 253-69, at 253.

28 John Law, Organizing Modernity (Oxford, Cambridge, I994) 83.

29 Law, Organizing, 95.

30 Annemarie Mol, The Logic of Care. Health and the Problem of Patient Choice (London, 2008).

3 I Peter-Paul Verbeek, Op de vleugels van Icarus. Hoe techniek en moraal met elkaar meebewegen (Rotterdam, 20I4).

32 Ingrid Zechmeister, 'Foetal Images: The Power of Visual Technology in Antenatal Care and the Implications for Women's Reproductive Freedom', Health Care Analysis 9 (200 I) 387-400.

33 Paul van Trigt, 'A Blind Spot of a Guiding Country? Human Rights and Dutch Disability Groups since I98 I', Moving the Social 53 (2015) 87-I02; Troost, 'Erfelijke aandoeningen'.

34 Cf. Verstraete, In the Shadows; Joris van Eijnatten, Ed Jonker, Willemijn Ruberg and Joes Segal, 'Shaping the Discourse on Modernity', International Journal for History, Culture and Modernity I: I (2013) 3-20, at I7; Bill Hughes, 'The Constitution of Impairment: Modernity and the Aesthetic of Oppression', Disability \& Society, I4:2 (1999) I 55-72.

35 Cf. Dipesh Chakrabarty argues in Provincializing Europe (Princeton, 2000), 7 that the social and human sciences unconsciously reflect the socalled European intellectual tradition, in which global historical time is dominated by the 'first in Europe, then elsewhere' structure.

36 Shaun Grech, 'Decolonising Eurocentric Disability Studies: Why Colonialism Matters in the Disability and Global South Debate', Social Identities 2 I: I (2015) 6-2 I.

37 Annemarie Mol, The Body Multiple. Ontology in Medical Practice (Durham, 2002). Examples of the way Mol's work can be applied to disability history are Annemieke van Drent, 'The "Truth" About Idiocy: Revisiting Files 
of Children in the Dutch "School for Idiots" in the Nineteenth Century', History of Education 45:4 (20I6) 477-49I; Paul van Trigt and Susan Legêne, 'Writing Disability into Colonial Histories of Humanitarianism', Social Inclusion 4:4 (2016) I 88-96.

38 Dan Goodley and Katherine Runswick-Cole, 'Becoming Dishuman: Thinking About the Human Through Dis/ability', Discourse: Studies in the Cultural Politics of Education 37: I (20I4), I-I5; Bill Hughes and Kevin Paterson, 'The Social Model of Disability and the Disappearing Body: Towards a Sociology of Impairment', Disability \& Society I2:3 (I997) 325-40; Verstraete, In the shadows.

39 Helen Meekosha and Karen Soldatic, 'Human Rights and the Global South: The Case of Disability', Third World Quarterly 32:8 (20 I I) I383-97, at I385; cf. Raewyn Connell, 'Southern Bodies and Disability: Re-thinking Concepts', Third World Quaterly 32:8 (20 I I) I369-8 I .

40 Jane Campbell and Mike Oliver, Disability Politics: Understanding Our Past, Changing Our Future (London, I996).

4I Bill Hughes, 'Disability and the Body', Colin Barnes, Mike Oliver and Len Barton (eds), Disability Studies Today (Cambridge, 2002) 58-76.

42 Vasilis Galis, 'Enacting Disability: How Can Science and Technology Studies Inform Disability Studies', Disability \& Society 26: 7 (20 I I) 825-38.

43 Galis, 'Enacting Disability'826; M. Corker and T. Shakespeare, 'Mapping the terrain', in M. Corker and T. Shakespeare (eds), Disability / postmodernity (London, I999) I-I 7.

44 Galis, 'Enacting Disability', 826.

45 Ibid., 830.

46 Bruno Latour, Reassembling the Social. An Introduction to Actor-NetworkTheory (Oxford, 2005) I.

47 Ibid., 36, 48.

48 Ibid., 9I.

49 Ibid., I09.

50 Ibid., 36.

5I Van Trigt, 'Historicizing the Social Model'; cf. Katharina Heyer, Rights Enabled. The Disability Revolution, from the US, to Germany and Japan, to the United Nations (Michigan, 20 I5); Steven Epstein, Impure Science: AIDS, Activism, and the Politics of Knowledge (Berkeley, I996).

52 Van Eijnatten et al, 'Shaping the Discourse on Modernity', I7.

53 Hughes, 'Social model'; Hudges, 'Disability'.

54 Shakespeare, Disability, 5. 
55 Ibid., 59.

56 Annemarie Mol, 'Ontological Politics. A Word and Some Questions', in J. Law and J. Hassard (eds), Actor network theory and after (Oxford, I999) 74-89; Mol, Body Multiple; Mol, Logic of Care.

57 Peter Skafish, 'The Metaphysics of Extra-Moderns. On the Decolonization of Thought- A Conversation with Eduardo Vivieros de Castro', Common Knowledge 22:3 (2016) 393-4I4, at 395.

58 Galis, 'Enacting Disability', 825.

59 Roger Cooter and Claudia Stein, Writing History in the Age of Biomedicine (New Haven and London, 2013) 2 I6.

60 Ibid., 2 I 8.

6I Ibid., 2 I9.

62 Ibid., 219

63 Ibid., 22 I.

64 Ibid., 226.

65 Annemarie Mol and Jessica Mesman, 'Neonatal Food and the Politics of Theory: Some Questions of Method', Social Studies of Science 26 (I996) 419-44.

66 Mol, Logic of Care; Mol, 'Ontological Politics'.

\section{About the Author}

Paul van Trigt has published on the history of the welfare state, human rights, disability and religion. He currently works at Leiden University as a postdoctoral researcher in the project 'Rethinking Disability: the Impact of the International Year of Disabled Persons (I98I) in Global Perspective', funded by the ERC. He is writing a genealogy of the United Nations Convention on the Rights of Persons with Disabilities. E-mail: p.w.van.trigt@hum.leidenuniv.nl 